\title{
BRAF Mutations and their Implications in Molecular Targeting Therapies for Gastrointestinal Cancers
}

\section{Shouji Shimoyama*}

Gastrointestinal Unit, Settlement Clinic, 4-20-7, Towa, Adachi-ku, Tokyo, 120-0003, Japan

The epidermal growth factor receptor (EGFR) has become an important therapeutic target in gastrointestinal cancers, especially in colorectal cancer. Stimuation of the EGFR activates at least five intracellular signal cascades such as RAS/RAF/MEK(mitogen-activated ERK activating kinase)/ERK(extracellular signal-regulated kinase), PI3K (phosphatidylinositol 3-kinase) /PTEN (phosphatase and tensin homolog)/AKT(v-akt murine thymoma viral oncogene homolog), STAT (signal transducer and activator of transcription), pospholipase C, and SRC/FAK(focal adhesion kinase). These either phosphorylate their target proteins in the cytoplasm or transmit signals from growth factor receptor to the nucleus, thereby initiating subsequent expression of genes that regulate cell proliferation, differentiation, angiogenesis, and survival [1].

Recently, monoclonal antibodies have been developed to target EGFR and to inhibit subsequent cellular responses. They include anti-EGFR antibodies such as cetuximab (a chimeric monoclonal immunoglobulin G1 antibody), panitumumab (a fully human monoclonal immunoglobulin G2 antibody), and trastuzumab (a monoclonal antibody against human epidermal growth factor receptor-2 (HER2) as well as inhibitors of tyrosine kinase (TK) domain of EGFR or subsequent molecules such as gefitinib, erlotinib (both inhibitors of EGFR-TK), lapatinib (a dual inhibitor of HER2-TK and EGFR-TK), sunitinib (an inhibitor of the TK of various kinds of proteins), and sorafenib (an inhibitor of RAF, a downstream molecular of RAS). Among these, cetuximab, panitumumab, and trastuzumab have received the most intensive focus of research, and their efficacy has been clearly demonstrated -especially in gastric and colorectal cancer. However, it is also a fact that this efficacy is sometimes modest as objective response rates comprise at best $50 \%$ by adding trastuzumab to chemotherapy -even among HER-2 positive gastric cancer patients [2], or between 8 and $11 \%$ by cetuximab $[3,4]$ or pamitumumab $[5,6]$ monotherapy in colorectal cancer patients. The efficacy is thus presumed to be restricted to a certain segment of patients. Therefore, identification of predictive markers of response and resistance in performing the EGFR targeting therapies is urgently needed to stratify those patients benefiting most from them. This in turn obviate unnecessary or futile treatment and reduce health care costs, ultimately allowing treatment to be individualized.

Components of the signal transduction cascade downstream to EGFR are sometimes mutated, which entails a continuous "switchon" state that triggers the aberrant activation of the cascades even in the absence of extracellular growth stimuli or in the presense of EGFR inhibition. For example, the benefit of cetuximab was limited to patients with wild type KRAS [7,8]. In addition, KRAS mutation predicted a lack of clinical benefit of panitumumab [6]. Accordingly, KRAS gene mutation is considered a predictor for the efficacy of antiEGFR therapies, and testing for KRAS gene mutation status prior to the use of anti-EGFR antibodies is needed to distinguish between patients with the highest chance of benefiting from them and those for whom the administration would be presumably ineffective [7].
Despite the informative inverse association between KRAS mutation status and response to anti-EGFR therapies, only a subset of wild type KRAS carriers are responders to the anti-EGFR therapies, the objective response rates being $13-28 \%$ for cetuximab monotherapy $[4,9], 44-61 \%$ for cetuximab in combination with chemotherapy [10-12], 17-29\% for panitumumab monotherapy [6,13,14], and 35$55 \%$ for panitumumab in combination with chemotherapy $[15,16]$. It is hypothesized that mutations in genes other than KRAS that are involved in the signal transduction cascade may account for the resistance to anti-EGFR therapies. In this regard, mutation analyses for RAF proteins, downstream proteins to KRAS in the MEK/ERK pathway, have been attractive targets for patient selection before considering anti-EGFR therapies because KRAS and BRAF mutation is usually mutually exclusive [17-19] - although double mutation of KRAS and BRAF does occur in some colorectal cancers [20]. The clinical relevance of BRAF mutation has been confirmed by several recent clinical studies demonstrating that anti-EGFR therapies resulted in a lack of response [17,21,22] and shorter survival [23-25] among patients harboring wild-type KRAS but mutant BRAF. The BRAF mutations could therefore provide useful information for predicting resistance to anti-EGFR therapies among patients bearing wild-type KRAS. How BRAF mutations work and contribute to initiate signal transduction cascades leading to resistance to anti-EGFR therapies has been most intensively investigated in malignant melanoma treatment. Extrapolation of the knowledge concerning malignant melanoma to gastrointestinal cancers could provide the next breakthrough in the field of molecular targeting therapies against gastrointestinal cancers.

The RAF gene family consists of ARAF, BRAF, and Raf-1 (formerly known as CRAF). All three proteins are serine/threonine kinases located in the RAS/RAF/MEK/ERK cascade as downstream effectors of RAS and are able to phosphorylate and activate MEK, which in turn activates ERK. These three RAF proteins exhibit different biochemical potencies, and BRAF is the most potent activator of MEK [26-28].

Table 1 lists the details of BRAF mutation reported in the COSMIC database (http://www.sanger.ac.uk/genetics/CGP/cosmic/) [29]; the incidence of BRAF somatic mutations varies considerably among malignancies. The BRAF mutations occur at particularly high frequencies in malignant melanoma or in papillary thyroid cancer, with estimated incidences ranging from 30 to $70 \%[29,30]$ and from

*Corresponding author: Shouji Shimoyama, M.D, Gastrointestinal Unit, Settlement Clinic, 4-20-7, Towa, Adachi-ku, Tokyo, 120-0003, Japan, Tel: +81-33605-7747; Fax: +81-3-3605-0244; E-mail: shimoyama@apost.plala.or.jp

Received May 31, 2011; Accepted June 03, 2011; Published June 06, 2011

Citation: Shimoyama S (2011) BRAF Mutations and their Implications in Molecular Targeting Therapies for Gastrointestinal Cancers. J Pharmacogenom Pharmacoproteomics 2:e102. doi:10.4172/2153-0645.1000e102

Copyright: (C) 2011 Shimoyama S. This is an open-access article distributed under the terms of the Creative Commons Attribution License, which permits unrestricted use, distribution, and reproduction in any medium, provided the original author and source are credited. 
Citation: Shimoyama S (2011) BRAF Mutations and their Implications in Molecular Targeting Therapies for Gastrointestinal Cancers. J Pharmacogenom Pharmacoproteomics 2:e102. doi:10.4172/2153-0645.1000e102

\begin{tabular}{|c|c|c|c|c|c|c|c|c|c|c|c|c|}
\hline & & & \multicolumn{10}{|c|}{ Number of mutations } \\
\hline Tumor type & & & Total & Colorectal & Thyroid & $\begin{array}{l}\text { Malignant } \\
\text { melanoma }\end{array}$ & Lung & Ovary & Prostate & Stomach & Esophagus & Others \\
\hline $\begin{array}{l}\text { number of total } \\
\text { samples }\end{array}$ & & & 66505 & 33505 & 16350 & 5936 & 3526 & 1225 & 1129 & 933 & 83 & 3818 \\
\hline $\begin{array}{l}\text { number of any } \\
\text { mutation }\end{array}$ & & & 13983 & 3570 & 7463 & 2654 & 79 & 56 & 42 & 11 & 2 & 106 \\
\hline $\begin{array}{l}\text { number of V600 } \\
\text { mutation }\end{array}$ & & & 13496 & 3478 & 7411 & 2421 & 34 & 41 & 42 & 9 & 2 & 58 \\
\hline $\begin{array}{l}\text { number of } \mathrm{V} 600 \mathrm{E} \\
\text { mutation }\end{array}$ & & & 13157 & 3476 & 7411 & 2139 & 34 & 39 & 4 & 4 & 2 & 48 \\
\hline $\begin{array}{l}\text { any mutation/ } \\
\text { total, \% }\end{array}$ & & & $21 \%$ & $11 \%$ & $46 \%$ & $45 \%$ & $2 \%$ & $5 \%$ & $4 \%$ & $1 \%$ & $2 \%$ & $3 \%$ \\
\hline $\begin{array}{l}\text { V600/any } \\
\text { mutation, \% }\end{array}$ & & & $97 \%$ & $97 \%$ & $99 \%$ & $91 \%$ & $43 \%$ & $73 \%$ & $100 \%$ & $82 \%$ & $100 \%$ & $55 \%$ \\
\hline $\begin{array}{l}\text { V600E/any } \\
\text { mutation, \% }\end{array}$ & & & $94 \%$ & $97 \%$ & $99 \%$ & $81 \%$ & $43 \%$ & $70 \%$ & $10 \%$ & $36 \%$ & $100 \%$ & $45 \%$ \\
\hline SUBSTITUTIONS & & & & & & & & & & & & \\
\hline position & wt AA & mt AA & & & & & & & & & & \\
\hline 201 & Q & $\mathrm{H}$ & 1 & & & & & 1 & & & & \\
\hline 326 & I & $\mathrm{T}$ & 2 & & & & & & & & & $2(\mathrm{Br})$ \\
\hline 421 & G & V & 1 & & & & 1 & & & & & \\
\hline 439 & $\mathrm{~K}$ & $\mathrm{Q}, \mathrm{T}$ & 2 & & & 1 & 1 & & & & & \\
\hline 440 & $\mathrm{~T}$ & $P$ & 1 & & & & 1 & & & & & \\
\hline 443 & $\mathrm{R}$ & $\mathrm{T}$ & 1 & & & & & & & & & 1(En) \\
\hline 444 & $\mathrm{R}$ & $\mathrm{Q}, \mathrm{R}, \mathrm{W}$ & 4 & & & 2 & & & & & & 2(En) \\
\hline 447 & S & S & 1 & 1 & & & & & & & & \\
\hline 456 & Q & Q & 1 & & 1 & & & & & & & \\
\hline 459 & V & $\mathrm{L}$ & 1 & & & & 1 & & & & & \\
\hline 462 & $\mathrm{R}$ & I & 2 & 1 & & & & & & & & 1(En) \\
\hline 463 & I & S & 1 & 1 & & & & & & & & \\
\hline 464 & G & $E, R, V$ & 13 & 3 & & 1 & & 2 & & & & $1(\mathrm{Ae}) 5(\mathrm{Br}) 1(\mathrm{Ad})$ \\
\hline 466 & G & $A, E, R, V$ & 20 & & & 10 & 8 & & & & & $1(\mathrm{C}) 1(\mathrm{GI})$ \\
\hline 467 & S & L & 1 & & & 1 & & & & & & \\
\hline 468 & $\mathrm{~F}$ & $\mathrm{C}, \mathrm{S}$ & 2 & 2 & & & & & & & & \\
\hline 469 & G & $A, E, R, S, V$ & 35 & 7 & 1 & 10 & 13 & & & & & 1(Ae)1(C)2(Bi) \\
\hline 471 & V & $\mathrm{F}$ & 3 & & & & 3 & & & & & \\
\hline 472 & $\mathrm{Y}$ & $S$ & 5 & & & & & & & & & $5(E n)$ \\
\hline 475 & K & M & 1 & & & 1 & & & & & & \\
\hline 485 & $\mathrm{~L}$ & $\mathrm{~F}$ & 1 & & & 1 & & & & & & \\
\hline 529 & $\mathrm{~T}$ & A & 1 & 1 & & & & & & & & \\
\hline 581 & $\mathrm{~N}$ & I,S,Y & 7 & 4 & & 2 & & 1 & & & & \\
\hline 582 & I & M & 2 & & & 2 & & & & & & \\
\hline 583 & $\mathrm{~F}$ & $\mathrm{~F}$ & 4 & & & 4 & & & & & & \\
\hline
\end{tabular}


Citation: Shimoyama S (2011) BRAF Mutations and their Implications in Molecular Targeting Therapies for Gastrointestinal Cancers. J Pharmacogenom Pharmacoproteomics 2:e102. doi:10.4172/2153-0645.1000e102

\begin{tabular}{|c|c|c|c|c|c|c|c|c|c|c|c|c|}
\hline 584 & L & $F, L$ & 4 & & & 4 & & & & & & \\
\hline 585 & $\mathrm{H}$ & $\mathrm{H}$ & 1 & & & 1 & & & & & & \\
\hline 586 & $\mathrm{E}$ & $\mathrm{E}, \mathrm{K}$ & 6 & & & 5 & & 1 & & & & \\
\hline 587 & D & $A, E, N$ & 3 & 1 & & 2 & & & & & & \\
\hline 588 & L & $P, R$ & 2 & & & 2 & & & & & & \\
\hline 590 & V & I,V & 2 & & & 1 & & & & & & 1(Sal) \\
\hline 591 & K & $\mathrm{R}$ & 1 & & & & & & & & & $1(\mathrm{En})$ \\
\hline 592 & I & $\mathrm{M}, \mathrm{V}$ & 6 & & & 6 & & & & & & \\
\hline 593 & G & D & 2 & 1 & 1 & & & & & & & \\
\hline 594 & D & $\mathrm{E}, \mathrm{G}, \mathrm{K}, \mathrm{N}, \mathrm{V}$ & 32 & 18 & & 8 & 1 & 1 & & 2 & & 2(En) \\
\hline 595 & $F$ & L,S & 7 & 1 & & 5 & & & & & & $1(\mathrm{Bi})$ \\
\hline 596 & G & $D, R, S$ & 7 & 4 & & 1 & & & & & & $2(C)$ \\
\hline 597 & L & $L, Q, R, S, V$ & 33 & 2 & & 18 & 9 & 2 & & & & $1(\mathrm{C}) 1(\mathrm{Bi})$ \\
\hline 598 & A & $\mathrm{T}, \mathrm{V}$ & 4 & & 2 & 2 & & & & & & \\
\hline 599 & $\mathrm{~T}$ & I,T & 6 & 2 & & 4 & & & & & & \\
\hline 600 & V & $?, A, D, E, G, K, L, M, R$ & 13496 & 3478 & 7411 & 2421 & 34 & 41 & 42 & 9 & 2 & $\begin{array}{l}7(\mathrm{En}) 8(\mathrm{Ae}) 9(\mathrm{Br}) \\
3(\mathrm{U}) 5(\mathrm{P}) 22(\mathrm{Bi}) 2 \\
(\mathrm{~L}) 1(\mathrm{Ad}) 1(\mathrm{SI})\end{array}$ \\
\hline 601 & $\mathrm{~K}$ & $\mathrm{E}, \mathrm{I}, \mathrm{K}, \mathrm{L}, \mathrm{N}, \mathrm{Q}$ & 45 & 8 & 20 & 15 & 1 & 1 & & & & \\
\hline 602 & S & s & 1 & & & 1 & & & & & & \\
\hline 603 & $\mathrm{R}$ & * & 4 & & & & & & & & & $4(E n)$ \\
\hline 604 & W & G,S & 3 & & & 3 & & & & & & \\
\hline 605 & S & $\mathrm{F}, \mathrm{G}, \mathrm{N}, \mathrm{R}$ & 9 & 1 & & 8 & & & & & & \\
\hline 606 & G & $\mathrm{E}, \mathrm{G}, \mathrm{L}, \mathrm{R}$ & 5 & 1 & 1 & 2 & 1 & & & & & \\
\hline 607 & $S$ & $P$ & 1 & & & 1 & & & & & & \\
\hline 608 & $\mathrm{H}$ & $\mathrm{R}$ & 2 & & & 2 & & & & & & \\
\hline 609 & Q & $\mathrm{Q}, \mathrm{R},{ }^{*}$ & 3 & 1 & & 2 & & & & & & \\
\hline 610 & $\mathrm{~F}$ & s & 1 & & & 1 & & & & & & \\
\hline 611 & $\mathrm{E}$ & D & 1 & & & 1 & & & & & & \\
\hline 612 & $\mathrm{Q}$ & $E,{ }^{*}$ & 3 & & 2 & 1 & & & & & & \\
\hline 614 & $S$ & $\mathrm{P}, \mathrm{S}$ & 4 & & & 4 & & & & & & \\
\hline 615 & G & $\mathrm{R}$ & 2 & & & 2 & & & & & & \\
\hline 616 & $S$ & $\mathrm{P}, \mathrm{F}$ & 5 & & & 2 & & 1 & & & & $2(\mathrm{P})$ \\
\hline 617 & 1 & $\mathrm{~T}$ & 1 & & & 1 & & & & & & \\
\hline 618 & L & S,W & 8 & & & 3 & 1 & & & & & $4(E n)$ \\
\hline 619 & W & $\mathrm{R}$ & 1 & & & 1 & & & & & & \\
\hline 636 & $Q$ & E & 1 & & & & 1 & & & & & \\
\hline 637 & $S$ & * & 1 & & & & & 1 & & & & \\
\hline 682 & $\mathrm{R}$ & Q & 1 & & & & & & & & & 1(En) \\
\hline Insertion & & & 12 & & 7 & 4 & & & & & & $1(\mathrm{P})$ \\
\hline
\end{tabular}




\begin{tabular}{|l|l|l|l|l|l|l|l|l|l|l|l|}
\hline Deletion & & 9 & & 5 & & 1 & 1 & $1(\mathrm{~K}) 1(\mathrm{SI})$ \\
\hline Complex & & 15 & & 11 & 2 & 2 & \\
\hline Others & & 120 & 32 & 1 & 83 & & 3 & $1(\mathrm{En})$ \\
\hline
\end{tabular}

?:unknown, *:nonsense

En: endometorium, Ae: upper aerodigestive tract, Br: breast, BrIS: breast in situ, C: cervix, U: urinary tract, $\mathrm{P}$ : pancreas

K: kidney, Bi: biliary tract, L: liver, Sal: salivary gland, Ad: adrenal, SI: small intestine, GI: gastrointestinal tract

wt AA: wild type amino acid, mtAA: mutant amino acid

Table: BRAF mutation and detail of amino acid substitutions by tumor type listed in the COSMIC database [29].

40 to $70 \%$ (average, approximately $45 \%$ ) [29-32], respectively. BRAF mutations are described at a moderate but significant frequency in colorectal (3-20\%) [17,21-24,29,30], esophageal (2-11\%) [29,33], biliary tract $(10-20 \%)[29,30]$, and ovarian $(5-10 \%)$ cancers $[29,30]$. They also occur at lower frequency in a wide variety of cancers such as in the stomach (0-3\%) [29,33-36] and lung (2-3\%) [29,33,37]. On the other hand, no BRAF mutations have been found so far in in situ breast cancer [29]. Interestingly, several reports suggest ethnic differences in BRAF mutation frequencies in colorectal cancer, these being 1.7-4.9\% in China [38,39], 3.7\% in Poland [40], and 0-2\% in Iran [41,42], which contrast sharply with those in the Western hemisphere.

In general, BRAF mutation occurs predominantly to convert valine at amino acid position 600 to other amino acids [43,44]. Such a panel of V600 mutations - a substitution of valine by other amino acid, e.g., V600E, V600K, V600D, V600R- comprise $80-90 \%$ of all BRAF mutations $[43,44]$, and all are characterized as activating mutations [45]. Among them, a T1799A in exon 15 resulting in a substitution of glutamic acid (E) for valine (V) (V600E) (formerly referred to as the 599 position) $[43,44]$ is the most common, accounting for up to $90 \%$ of all BRAF mutations [44]. It is able to elicit a 480 -fold stronger phosphorylation activity in ERK than in wild type BRAF [45]. However, each malignancy exhibits different BRAF mutational spectra. V600E is common in malignant melanoma, thyroid cancer, and colorectal cancer, but it is comparatively rare in lung, prostate, and gastric cancers [29,37,44,46]. Mutations other than the V600 panel have been studied: some are hyperactive, but some display even decreased activity [45].

Neverthelss, it is worth noting that the hyperactive mutation (V600E) is the most predominant, and the absence of a V600E mutation is rather rare in human cancers. Such a high likelihood of "gain-offunction" mutation provides one explanation why BRAF mutation, even among wild-type KRAS carriers, is associated with resistance to anti-EGFR therapies and poor prognoses. The frequency and focality of this hyperactive mutation in certain cancers suggest its importance in cancer biology and potential as a therapy target.

Accordingly, several BRAF inhibitors have been developed and categorized as Pan-RAF inhibitors or BRAF specific inhibitors [47]. The efficacy of these inhibitors has been most extensively investigated in malignant melanoma. With regard to gastrointestinal cancers, several phase I/II studies are ongoing incorporating these inhibitors -alone or in combination with chemotherapeutic drugs- against colorectal, gastric, and esophageal cancers [48]. Despite some impressive clinical successes with the inhibitors $[49,50]$, treatment responsive patients ultimately relapse as a result of acquired resistance [50], as is also observed in other tyrosine kinase inhibitors [51]. Several plausible mechanisms have been offered for this resistance, including CRAF bypass signaling, other BRAF mutations which initiate the MEK/ ERK axis, mutations of genes in downstream RAF that aberrantly upregulate the axis, and activation of altenative prosurvival pathways that may drive proliferation and resistance to apoptosis, all resulting in compensating for BRAF inhibition and bypassing the MEK/ERK pathway.

Very recent findings [52-54] have shed light on the complexities and signaling cross-talk associated with the inhibition of the BRAF mutant. BRAF inhibitions conduct a unique conformational change homodimer (CRAF/CRAF) or heterodimer (BRAF/CRAF). Under conditions of BRAF specific inhibitors and KRAS mutation, the inhibited BRAF molecule acts as a scaffold to transmit signals from mutant KRAS by the drug free CRAF present in the dimmer, suggesting that CRAF acts as a BRAF effector and a stimulator of the MEK/ERK cascade dependent on the KRAS mutation. Several findings support this hypothesis. The BRAF/CRAF heterodimer has vastly elevated kinase activity compared with the respective monomers or honodimers [55]. In addition, an increase in CRAF expression in response to BRAF inhibitor AZ628 is observed, and CRAF activation and heterodimelization with BRAF constitute critical components of the cellular response to the BRAF inhibitor, leading to resistance to the drug [56]. Moreover, the inhibition of BRAF might cooperate with oncogenic RAS to induce tumor growth [54]. Therefore, the inactivation of BRAF, under conditions of KRAS mutation, can ultimately lead to activation of the MEK/ERK pathway [56,57]. These mechanisms highlight the necessity to consider the KRAS mutation status before any administration of BRAF inhibitors. Although patients with KRAS mutation are resistant to cetuximab or panitumumab, BRAF inhibitors as alternative targeted therapies may be also ineffective or even hazardous in such patients: BRAF inhibitors can activate the MEK/ERK pathway in patients harboring KRAS mutation and thus are preferably avoided. Genotyping both KRAS and BRAF prior to administering BRAF inhibitors is hugely encouraged.

In this situation, pan-RAF inhibitors may be of value because they target all RAF isoforms and concurrently inhibit CRAF. As described above, the BRAF selective inhibitor results in pathway reactivation through CRAF, though this is less likely to occur with pan-RAF inhibitors even under the condition of KRAS mutation because CRAF is also inhibited. Accordingly, careful consideration is required when determining who is to be treated with a BRAF specific inhibitor; under certain conditions, the strategy of using pan-RAF inhibitors may actually be the better option.

Tumors harboring a unique dependency in the activated oncogene and activated pathway often develop clinical resistance against targeting therapies through point mutation or genetic amplification of the targeted locus. Elaboration of such resistance mechanisms has revealed the design of inhibitors with more enhanced potencies against a range of resistant variants. Continued attempts should be made to explore the complete atlas of genetic events responsible for sustained cell growth and the way such events functionally interact. The development of drugs selected for patients on the basis of the specific 
molecular features for which a response is needed will establish new means to attack cancer and ultimately to tailor treatment -instead of the traditional "one-drug-fits-all" approach.

\section{References}

1. Laurent-Puig P, Lievre A, Blons $\mathrm{H}$ (2009) Mutations and response to epiderma growth factor receptor inhibitors. Clin Cancer Res 15: 1133-1139.

2. Bang YJ, Van Cutsem E, Feyereislova A, Chung HC, Shen L, et al. (2010) Trastuzumab in combination with chemotherapy versus chemotherapy alone for treatment of HER2-positive advanced gastric or gastro-oesophageal junction cancer (ToGA): a phase 3 , open-label, randomised controlled trial. Lancet 376: 687-697.

3. Cunningham D, Humblet $\mathrm{Y}$, Siena S, Khayat D, Bleiberg $\mathrm{H}$, et al. (2004) Cetuximab monotherapy and cetuximab plus irinotecan in irinotecan-refractory metastatic colorectal cancer. N Engl J Med 351: 337-345

4. Karapetis CS, Khambata-Ford S, Jonker DJ, O'Callaghan CJ, Tu D, et al. (2008) K-ras mutations and benefit from cetuximab in advanced colorectal cancer. N Engl J Med 359: 1757-1765.

5. Van Cutsem E, Peeters M, Siena S, Humblet Y, Hendlisz A, et al. (2007) Openlabel phase III trial of panitumumab plus best supportive care compared with best supportive care alone in patients with chemotherapy-refractory metastatic colorectal cancer. J Clin Oncol 25: 1658-1664.

6. Amado RG, Wolf M, Peeters M, Van Cutsem E, Siena S, et al. (2008) Wildtype KRAS is required for panitumumab efficacy in patients with metastatic colorectal cancer. J Clin Onco. 26: 1626-1634.

7. Allegra CJ, Jessup JM, Somerfield MR, Hamilton SR, Hammond EH, et al. (2009) American Society of Clinical Oncology provisional clinical opinion: testing for KRAS gene mutations in patients with metastatic colorectal carcinoma to predict response to anti-epidermal growth factor receptor monoclonal antibody therapy. J Clin Oncol 27: 2091-2096.

8. Jiang Y, Kimchi ET, Staveley-O'Carroll KF, Cheng H, Ajani JA (2009) Assessment of K-ras mutation: a step toward personalized medicine for patients with colorectal cancer. Cancer 115: 3609-1317.

9. De Roock W, Piessevaux H, De Schutter J, Janssens M, De Hertogh G, et al. (2008) KRAS wild-type state predicts survival and is associated to early radiological response in metastatic colorectal cancer treated with cetuximab. Ann Oncol 19: 508-515

10. Van Cutsem E, Köhne CH, Hitre E, Zaluski J, Chang Chien CR, et al. (2009) Cetuximab and chemotherapy as initial treatment for metastatic colorectal cancer. N Engl J Med 360: 1408-1417.

11. Bokemeyer C, Bondarenko I, Makhson A, Hartmann JT, Aparicio J, et al. (2009) Fluorouracil, leucovorin, and oxaliplatin with and without cetuximab in the firstline treatment of metastatic colorectal cancer. J Clin Oncol 27: 663-671.

12. Lièvre A, Bachet JB, Boige V, Cayre A, Le Corre D, et al. (2008) KRAS mutations as an independent prognostic factor in patients with advanced colorectal cancer treated with cetuximab. J Clin Oncol 26: 374-379.

13. Doi T, Tahara M, Yoshino T, Yamazaki K, Tamura T, et al. (2011) Tumor KRAS status predicts responsiveness to panitumumab in Japanese patients with metastatic colorectal cancer. Jpn J Clin Oncol 41: 210-216.

14. Benvenuti S, Sartore-Bianchi A, Di Nicolantonio F, Zanon C, Moroni M, et al. (2007) Oncogenic activation of the RAS/RAF signaling pathway impairs the response of metastatic colorectal cancers to anti-epidermal growth factor receptor antibody therapies. Cancer Res 67: 2643-2648.

15. Peeters M, Price TJ, Cervantes A, Sobrero AF, Ducreux M, et al. (2010) Randomized phase III study of panitumumab with fluorouracil, leucovorin, and irinotecan (FOLFIRI) compared with FOLFIRI alone as second-line treatment in patients with metastatic colorectal cancer. J Clin Oncol 28: 4706-4713

16. Douillard JY, Siena S, Cassidy J, Tabernero J, Burkes R, et al. (2010) Randomized, phase III trial of panitumumab with infusional fluorouracil, leucovorin, and oxaliplatin (FOLFOX4) versus FOLFOX4 alone as first-line treatment in patients with previously untreated metastatic colorectal cancer: the PRIME study. J Clin Oncol 28: 4697-4705.
17. Di Nicolantonio F, Martini M, Molinari F, Sartore-Bianchi A, Arena S, et al. (2008) Wild-type BRAF is required for response to panitumumab or cetuximab in metastatic colorectal cancer. J Clin Oncol 26: 5705-5712.

18. Rajagopalan H, Bardelli A, Lengauer C, Kinzler KW, Vogelstein B, et al. (2002) Tumorigenesis: RAF/RAS oncogenes and mismatch-repair status. Nature 418 934.

19. Thomas RK, Baker AC, Debiasi RM, Winckler W, Laframboise T, et al. (2007) High-throughput oncogene mutation profiling in human cancer. Nat Genet 39 347-351.

20. Oliveira C, Velho S, Moutinho C, Ferreira A, Preto A, et al. (2007) KRAS and BRAF oncogenic mutations in MSS colorectal carcinoma progression. Oncogene 26: 158-163.

21. Loupakis F, Ruzzo A, Cremolini C, Vincenzi B, Salvatore L, et al. (2009) KRAS codon 61,146 and BRAF mutations predict resistance to cetuximab plus irinotecan in KRAS codon 12 and 13 wild-type metastatic colorectal cancer. $\mathrm{Br}$ J Cancer 101: 715-721.

22. Laurent-Puig P, Cayre A, Manceau G, Buc E, Bachet JB, et al. (2009) Analysis of PTEN, BRAF, and EGFR status in determining benefit from cetuximab therapy in wild-type KRAS metastatic colon cancer. J Clin Oncol 27: 59245930.

23. Souglakos J, Philips J, Wang R, Marwah S, Silver M, et al. (2009) Prognostic and predictive value of common mutations for treatment response and survival in patients with metastatic colorectal cancer. Br J Cancer 101: 465-472.

24. Tol J, Nagtegaal ID, Punt CJ (2009) BRAF mutation in metastatic colorectal cancer. N Engl J Med 361: 98-99.

25. Van Cutsem E, Köhne CH, Láng I, Folprecht G, Nowacki MP, et al. (2011) cetuximab plus irinotecan, fluorouracil, and leucovorin as first-line treatment for metastatic colorectal cancer: updated analysis of overall survival according to tumor KRAS and BRAF mutation status. J Clin Oncol 29: 2011-2019.

26. Wellbrock C, Karasarides M, Marais R (2004) The RAF proteins take centre stage. Nat Rev Mol Cell Biol 5: 875-885

27. Marais R, Light Y, Paterson HF, Mason CS, Marshall CJ (1997) Differential regulation of Raf-1, A-Raf, and B-Raf by oncogenic ras and tyrosine kinases. J Biol Chem 272: 4378-4383.

28. Emuss V, Garnett M, Mason C, Marais R (2005) Mutations of C-RAF are rare in human cancer because C-RAF has a low basal kinase activity compared with B-RAF. Cancer Res 65: 9719-9726.

29. Catalogue Of Somatic Mutations In Cancer. Accessed, May 2011

30. Flaherty KT, McArthur G (2010) BRAF, a target in melanoma: implications for solid tumor drug development. Cancer 116: 4902-4913.

31. Mathur A, Moses W, Rahbari R, Khanafshar E, Duh QY, et al. (2011) Higher rate of BRAF mutation in papillary thyroid cancer over time: A single-institution study. Cancer.

32. Xing M (2005) BRAF mutation in thyroid cancer. Endocr Relat Cancer 12: 245 262.

33. Lea IA, Jackson MA, Li X, Bailey S, Peddada SD, et al. (2007) Genetic pathways and mutation profiles of human cancers: site- and exposure-specific patterns. Carcinogenesis 28: 1851-1858.

34. Kim IJ, Park JH, Kang HC, Shin Y, Park HW, et al. (2003) Mutational analysis of BRAF and K-ras in gastric cancers: absence of BRAF mutations in gastric cancers. Hum Genet 114: 118-120.

35. Lee SH, Lee JW, Soung YH, Kim HS, Park WS (2003) BRAF and KRAS mutations in stomach cancer. Oncogene 22: 6942-6945.

36. Zhao W, Chan TL, Chu KM, Chan AS, Stratton MR, et al. (2004) Mutations of BRAF and KRAS in gastric cancer and their association with microsatellite instability. Int J Cancer 108: 167-169.

37. Brose MS, Volpe P, Feldman M, Kumar M, Rishi I, et al. (2002) BRAF and RAS mutations in human lung cancer and melanoma. Cancer Res 62: 6997-7000.

38. Shen H, Yuan Y, Hu HG, Zhong X, Ye XX, et al. (2011) Clinical significance of K-ras and BRAF mutations in Chinese colorectal cancer patients. World $J$ Gastroenterol 17: 809-816. 
Citation: Shimoyama S (2011) BRAF Mutations and their Implications in Molecular Targeting Therapies for Gastrointestinal Cancers. J Pharmacogenom Pharmacoproteomics 2:e102. doi:10.4172/2153-0645.1000e102

Page 6 of 6

39. Liao W, Liao Y, Zhou JX, Xie J, Chen J, et al. (2010) Gene mutations in epidermal growth factor receptor signaling network and their association with survival in Chinese patients with metastatic colorectal cancers. Anat Rec (Hoboken) 293: 1506-1511.

40. Wójcik P, Okoń K, Osuch C, Klimkowska A, Tomaszewska R (2010) BRAF mutations in sporadic colorectal carcinoma from polish patients. Pol J Pathol 61: 23-26.

41. Naghibalhossaini F, Hosseini HM, Mokarram P, Zamani M (2011) High Frequency of Genes' Promoter Methylation, but Lack of BRAF V600E Mutation among Iranian Colorectal Cancer Patients. Pathol Oncol Res.

42. Brim H, Mokarram $P$, Naghibalhossaini F, Saberi-Firoozi M, Al-Mandhari M, et al. (2008) Impact of BRAF, MLH1 on the incidence of microsatellite instability high colorectal cancer in populations based study. Mol Cancer 7: 68.

43. Davies H, Bignell GR, Cox C, Stephens P, Edkins S, et al. (2002) Mutations of the BRAF gene in human cancer. Nature 417: 949-954.

44. Garnett MJ, Marais R (2004) Guilty as charged: B-RAF is a human oncogene. Cancer Cell 6: 313-319.

45. Wan PT, Garnett MJ, Roe SM, Lee S, Niculescu-Duvaz D, et al. (2004) Mechanism of activation of the RAF-ERK signaling pathway by oncogenic mutations of B-RAF. Cell 116: 855-867.

46. Paik PK, Arcila ME, Fara M, Sima CS, Miller VA, et al. (2011) Clinical characteristics of patients with lung adenocarcinomas harboring BRAF mutations. J Clin Oncol 29: 2046-2051.

47. Shepherd C, Puzanov I, Sosman JA (2010) B-RAF inhibitors: an evolving role in the therapy of malignant melanoma. Curr Oncol Rep 12: 146-152.

48. http://www.clinicaltrial.gov.
49. Bollag G, Hirth P, Tsai J, Zhang J, Ibrahim PN, et al. (2010) Clinical efficacy of a RAF inhibitor needs broad target blockade in BRAF-mutant melanoma. Nature 467: 596-599.

50. Flaherty KT, Puzanov I, Kim KB, Ribas A, McArthur GA, et al. (2010) Inhibition of mutated, activated BRAF in metastatic melanoma. N Engl J Med 363: 809819

51. Engelman JA, Settleman J (2008) Acquired resistance to tyrosine kinase inhibitors during cancer therapy. Curr Opin Genet Dev 18: 73-79.

52. Hatzivassiliou G, Song K, Yen I, Brandhuber BJ, Anderson DJ, et al. (2010) RAF inhibitors prime wild-type RAF to activate the MAPK pathway and enhance growth. Nature 464: 431-435.

53. Poulikakos PI, Zhang C, Bollag G, Shokat KM, Rosen N (2010) RAF inhibitors transactivate RAF dimers and ERK signalling in cells with wild-type BRAF. Nature 464: 427-430.

54. Heidorn SJ, Milagre C, Whittaker S, Nourry A, Niculescu-Duvas I, et al. (2010) Kinase-dead BRAF and oncogenic RAS cooperate to drive tumor progression through CRAF. Cell 140: 209-221.

55. Rushworth LK, Hindley AD, O'Neill E, Kolch W (2006) Regulation and role of Raf-1/B-Raf heterodimerization. Mol Cell Biol 26: 2262-2272.

56. Montagut C, Sharma SV, Shioda T, McDermott U, Ulman M, et al. (2008) Elevated CRAF as a potential mechanism of acquired resistance to BRAF inhibition in melanoma. Cancer Res 68: 4853-4861.

57. Dumaz N, Hayward R, Martin J, Ogilvie L, Hedley D, et al. (2006) In melanoma, RAS mutations are accompanied by switching signaling from BRAF to CRAF and disrupted cyclic AMP signaling. Cancer Res 66: 9483-9491. 